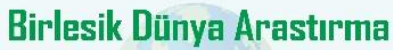 BD-CENTER \\ World Journal on Educational \\ Technology: Current Issues
}

www.wj-et.eu

\section{The risks and threats of digital educational technologies and products}

Elena A. Sorokoumova ${ }^{a}{ }^{*}$, Moscow Pedagogical State University, Moscow, Russia. https://orcid.org/0000-0002$\underline{2060}$

Elena B. Puchkova ${ }^{\text {b }}$, Moscow Pedagogical State University, Moscow, Russia https://orcid.org/0000-0001-9540$\underline{9893}$

Elena I. Cherdymova ${ }^{c},{ }^{3}$ Samara National Research University named after Academician S.P. Koroleva (Samara University, SSAU), Samara, Russia. / Moscow Pedagogical State University, Moscow, Russia. https://orcid.org/0000-0002-0392-8483

Larisa V. Temnovad, Lomonosov Moscow State University, Moscow, Russia https://orcid.org/0000-0002-3417$\underline{2594}$

\section{Suggested Citation:}

Sorokoumova, E.A., Puchkova, E.B., Cherdymova, E.C. \& Temnova, L.V. (2021). The risks and threats of digital educational technologies and products. World Journal on Educational Technology: Current Issues. 13(4), 0852-863. https://doi.org/10.18844/wjet.v13i4.6270

Received from July 31, 2021; revised from August 15, 2021; accepted from October 05, 2021

Selection and peer review under responsibility of Prof. Dr. Servet Bayram, Yeditepe University, Turkey.

(C)2021 Birlesik Dunya Yenilik Arastirma ve Yayincilik Merkezi. All rights reserved.

\begin{abstract}
Modern research is paying much attention to the issue of digital addiction of students in recent times since it can lead students to pay less attention to their academics. This article intends to discuss the possible threats and risks of the formation of digital dependence among teenagers from the use of gadgets. As a research method, the questionnaire method was used. The participants consisted of 13 specialists and 508 teenagers aged 11 to 14, studying in the 5th-8th grades of secondary schools. From the study, digital education increased the time spent of digital devices and technology. The authors also found that when students are learning with digital devices, they waste time on non-educational contents. The authors of the article propose psychological and pedagogical measures aimed at preventing digital addiction of students.
\end{abstract}

Keywords: students, digital educational technologies, digital products, Internet addiction, prevention, gadget, typology of threats and risks.

* ADDRESS FOR CORRESPONDENCE: Elena A. Sorokoumova, Moscow Pedagogical State University, Moscow, Russia.

E-mail address: cea51@mail.ru 


\section{Introduction}

Currently, the information society represents a new historical phase of civilization development, in which information and knowledge remain the main products of educational technologies. The development of information and communication technologies determines the essence of social transformations: changing of values, style, quality of life, and the development of one of the serious negative aspects of digital educational technologies - digital addiction. The formation of the information society is based on the steady improvement of information and communication technologies, - in particular - the use of digital resources in the educational process (Yermilova et al., 2019). Huge achievements in the information sphere have caused the formation of a new type of literacy that determines success in the labor market, and the requirements for personal qualities have changed (Akimova \& Shcherbin, 2018; Kozlova, 2018; Kalugina et al., 2018; Bagautdinova \& Nikulin, 2018; Akhmetova \& Nevskaya, 2018; Kvon et al., 2019; Piralova et al., 2019; Kornilov, 2017). Such qualities as the ability to find and collect information for solving a problem, the ability to analyze and generalize, the ability to quickly navigate in the global information space have come to the fore (Voiskunsky, 2002; Govorukhina, 2004; Bayanova et al., 2019a; Tugun et al., 2020; Nguyen et al., 2021; Shmal \& Zhivko, 2021).

The model of culture and knowledge transfer has changed - the younger ones teach the older ones to master information technologies (Aidarbekova et al., 2021). This tendency is also noted in educational practice: by the beginning of training, modern first-graders have already 3-4 years' experience in the use of digital technologies, and with the beginning of training, their digital skills grow even faster because it is determined by the requirements of training programs. As students grow older, they increasingly use digital technologies for educational purposes, while the variety of using the possibilities of the virtual world and the intensity of using gadgets in teaching environment is much less (Aidarbekova et al., 2021). In connection with the intensification of using the possibilities of the virtual world by young people, there is a problem of balance between rational use and the risk of developing Internet addiction (Lopez-Fernandez \& Kuss, 2020). In the context of modern social policy, domestic and foreign researchers have repeatedly proved that social prevention is a system of preventive measures, the main purpose of which is to prevent certain phenomena or processes.

According to scientists, social prevention has a significant social, economic and psychological effect. Attention to social prevention is the result of rejection from the previous medical model, which focused only on the treatment of the disease and dominated in many areas, and the formation of a new model, in the center of which stands the individual (Spirkina, 2008; Khomeriki \& Smirnova, 2010; Ursu \& Khudyakov, 2009). The Internet gives an individual the opportunity to build any world, to design selfpresentation., to test it in virtual networks, and the opportunity to set the rules of the game himself. Anonymity and the boundlessness of temporal and spatial characteristics create a deep gap between the real and virtual world, which is almost impossible for a student to overcome in his own (Nefedovskaya, 2007; Bespalko, 2002; Makarov, 2016; Bayanova et al., 2019b).

Since students tend to go into the virtual space, the introduction of new digital educational technologies will help expanding the time frame for students to use the Internet and gadgets of various kinds. In addition, often, in order to better assimilate knowledge by students, teachers introduce game elements into digital technologies, and gaming, which is the most common form of digital addiction 
among students, due to the fascination of many games and the possibility of auto-identification with various characters, will also move to the educational field (Voiskunsky \& Bogacheva, 2012; Karpova, 2017; Bayanova et al., 2019b; Shmal, 2020).

In addition, it should be noted that moving away from life problems into virtual reality negatively affects the development of students: the ability to engage in communication with peers, to find a way out in a difficult situation, and to correctly identify yourself as a person. Thus, it is possible to schematically represent the threats and risks of the formation of gadget dependence among students during the use of digital technologies in the educational process and everyday life (figure 1).

Possible threats and risks of the formation of digital dependence among students

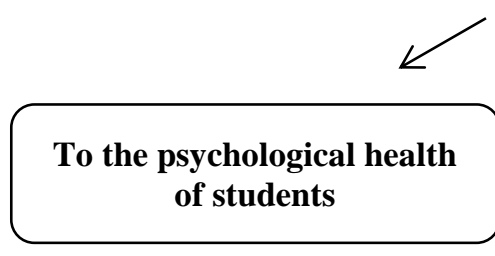

$\downarrow \vee$
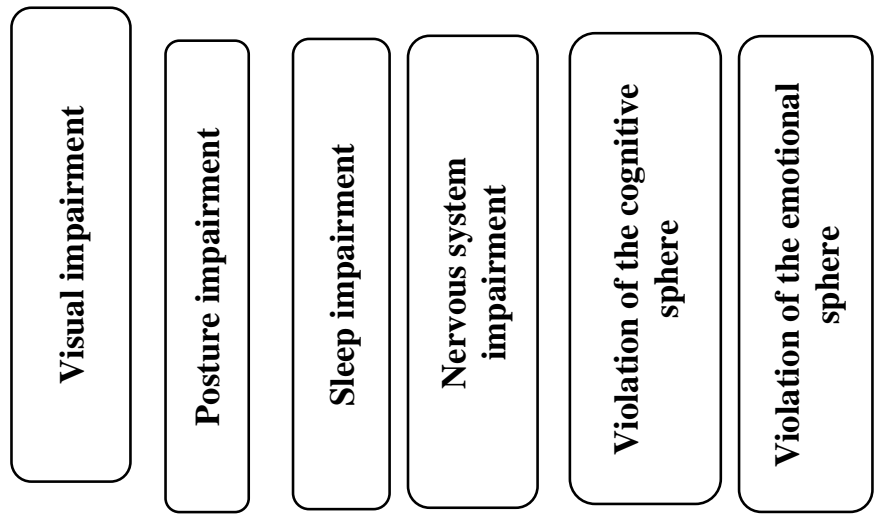

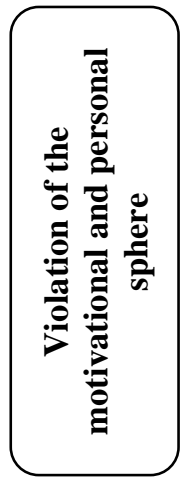

To the psychological health of students

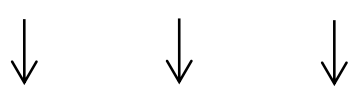
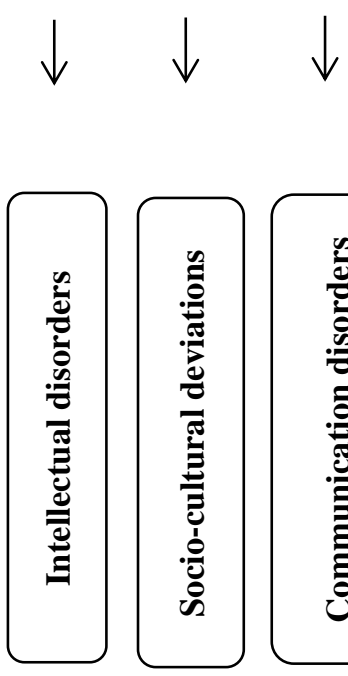

To the social health of students

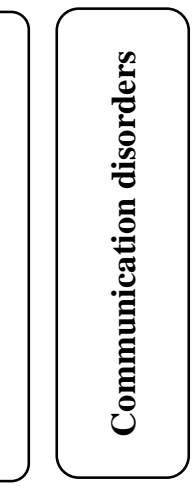

Figure 1. A typology of possible threats and risks of the formation of digital dependence among students 


\section{Theoretical Framework}

A new information age has brought new risks. Now, in the scientific world, previously unknown dangers are seriously discussed - the emergence of dependence on the virtual world, loneliness and insecurity in the real world, depersonalization of communication, withdrawal from reality, etc. In Russia, the problem of digital addiction does not have the official status, but monographs, dissertations, articles, conferences with the participation of foreign specialists testify to the research and scientificpractical interest in this topic. The active introduction of information technologies into the social life leads to qualitative changes in it. There is an expansion of the boundaries of communication in all spheres, an expansion of cooperation in business, science, culture and education.

According to the concept of the "end of the labor society", a new type of society is determined primarily by the development of the service sector, which improves the quality of life of both the individual and society as a whole. Interpersonal relationships are seriously changing. Long-term (family) and medium-term close (friendly, neighborly, professional) relationships are replaced by short-term acquaintances without attachment and responsibility, in which each of the participants is easily replaced. Direct "live" communication gives way to the communication mediated by gadgets, computers, etc. For some, such relationships become dominant. The range of methods and mechanisms for finding types of employment, work and partners is growing. The growth of well-being and love of travelling make it easy to change your place of residence, occupation, etc. (Shumakova, 2011; Sorokoumova, 2019; Temnova \& Puchkova, 2019).

Thus, the formation of a new level and quality of life of an individual and society is a positive change that has become possible thanks to the development of information, communication technologies and the Internet. In life situations of certain groups of people, they face some negative factors or their combination act more intensively. Such groups are called risk groups: social, pedagogical, psychological, etc. The analysis of risk factors helps to determine the mechanisms of action of these factors and measures to protect against them. Depending on which factors or behavioral characteristics of the individual are determining, the types of risk groups are formed (Chudova, 2002; Khomeriki, 2013).

In the Soviet period, when the interests of society were the main ones, risk groups were determined by the degree of potential danger to others and society as a whole. In recent years, the point of view of specialists has changed: the subject of the study has become an individual, i.e. unfavorable living conditions that put his life, health, condition of existence and development at risk. The problems that social prevention solves include the whole set of deviations and negative phenomena of public life, including various types of addiction: alcoholism, drug addiction, Internet addiction and others. The objectives of social prevention are to purposefully assist the participants of the risk group in their integration into society, in the formation of a positive value system for them, which should become the basis for self-realization and the development of social skills for the prevention of deviant behavior (Bukhanovsky, 2002; Egorov, Kuznetsova \& Petrova, 2005; Aibazova \& Karasova, 2018; Bayanova et al., 2020; Dmitriev, Kalinina \& Krotova, 2016; Ivanov, 2007).

Prevention means scientifically based and timely actions aimed at preventing possible physical, psychological or socio-cultural deviations among individuals and risk groups, as well as preserving, maintaining and protecting the normal standard of living and people's health, assisting individuals in achieving their goals and revealing their internal potentials (Niankara \& Niankara, 2020). The importance of prevention is to find optimal solutions both to achieve the goals and to prevent predictable problems. 
Several researchers have taken the time to study the prospects and perils of digitalization in education. For example, in the research of Ivanova \& Ivanov (2020), they explained that education could harm humanity rather than support it. They suggested that there is a need to design the educational system such that it complements the current state of technology. Ustyuzhanina \& Evsukov, (2018) also purported that the digitization of education could lead to the transfer of implied knowledge. Kotlyarova, Rudenko, Yaksa \& Shubina (2021) also expressed that digitalization of the Russian education could lead to spiritual lumpenization of the society, hence the need to build a proper structure for digital education in Russia.

\section{Objectives of the Research}

The main objectives of the research were: analysis of threats and risks of the formation of digital dependence among students when using gadgets in the educational process; analysis of educational technologies aimed at preventing digital dependence among students. Such serious attention to digital addiction is due to the fact that it has a destructive effect on the student's personality and on the process of his socialization. The student is able to think creatively and actively engage in work that arouses interest. In a situation of digital dependence, the student moves in the opposite direction: instead of searching for live communication or virtual interlocutors, companions, partners, or rivals or mastering the living space, they avoid difficulties, closing in his own world, rather than searching and testing ways to solve difficult situations in communication with other students.

\section{Methods and Materials}

This research was a quantitative research study with the main research method being a questionnaire survey. The research involved 503 teenagers aged 11 to 14 , studying in the 5th-8th grades of secondary schools and 13 specialists who work in educational institutions (teachers, psychologists, social workers).

\section{Data collection procedure}

At the first stage of the research, a questionnaire was structured according to blocks, aimed at investigating possible threats and risks of the formation of digital addiction, and the questions were formulated.

The questionnaire is a tool containing a structurally organized set of questions that reveal the essence of the tasks of the conducted research.

The questionnaire offers the following questions:

- Do you often have to access the Internet and use gadgets during your studies?

- How often do they give tasks at school that require the use of gadgets?

- Has the time spent on the Internet during training increased?

- Do you think that you often do not have enough time spent online?

- What gadgets do you mainly use for homework?

- What gadgets do you mainly use for extracurricular activities?

- Do you want to increase the time for working on the Internet? 
- Has the time of using gadgets during the educational process increased?

- Do you notice that other people around you spend a lot of time on the Internet?

- Do you think this is a problem?

- What directions of work, in your opinion, can be most effective for the prevention of digital addiction among students?

- What other directions and forms of prevention of digital addiction among students can you offer?

At the second stage of the research a sample was formed. At the third stage, a pilot research was conducted. The following results were obtained in it. Almost all the research participants (89\%) face cases of digital addiction. Moreover, in every third case, respondents note that digital addiction is observed among teenagers (31\%). At the same time, teenagers themselves note that they began to use gadgets more during studying and in everyday life. In addition, teenagers note that they mainly use phones to do homework (79\%), and computers (81\%), tablets (13\%) for extracurricular activities. It can be concluded that greater eye strain due to the use of phones with a smaller screen (compared to tablets and computers) is caused by homework, but we should not forget about the time interval (often longer) spent on games, which also does not affect vision in the best way.

\section{Results}

\section{Results on addiction}

The frequency of interaction with Internet addicts varies from one specialist to another, $23 \%$ of specialists say that they work with an addict at least once a month. The remaining $67 \%$ encounter seldom and observe manifestations of dependence in different individuals.

Almost all the survey participants $(97 \%)$ confirmed that they did not fill in any observation cards or stories of digital addiction of clients, did not take part in special tests, but determined the problem of digital addiction based on their already existing experience of working with such people, or on the basis of what they told about the student. It should be especially emphasized that all respondents identified the problem of digital addiction among students as extremely important. Digital addiction, according to the respondents, can become the basis for the development of deviant behavior. Students may experience problems in a general education institution. Disturbing facts, according to the experts, are the frequency and order of access to games or sites.

It is considered that initially attention to Internet sites and games takes only free time of a student. However, in the future, this free time increases due to other types of activities of a student (study, sleep, physical activity).

\section{Teenagers' responses on the importance of preventive measures of digital addiction}

A separate block of questions in the questionnaire concerned the prevention of digital addiction, its levels and purpose (Figure 2). 


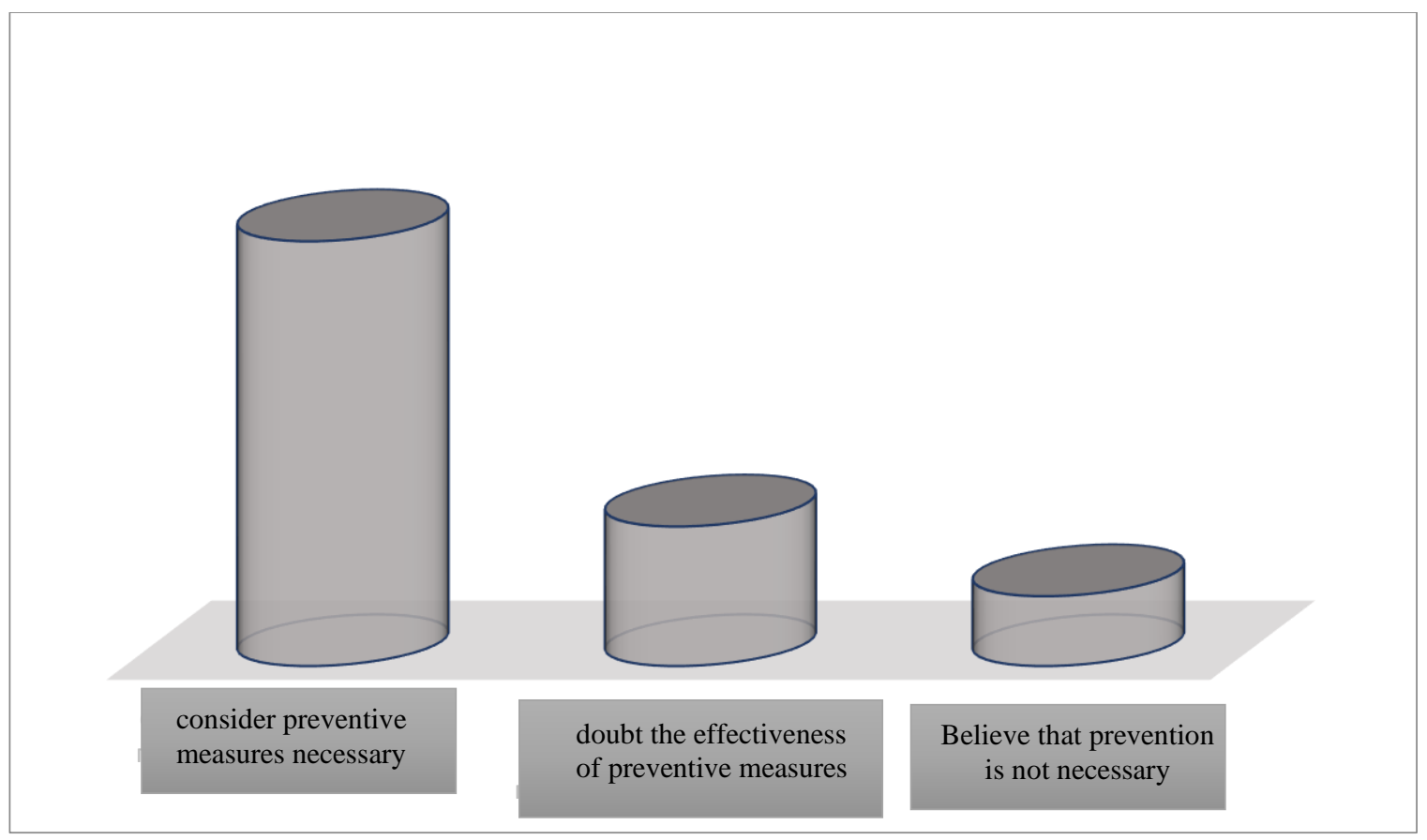

Figure 2. Teenagers' responses on the importance of preventive measures in relation to digital addiction

First of all, it should be noted that absolutely all the survey participants recognize the need for social prevention of digital addiction. More than half (67\%) of respondents consider it appropriate to carry out preventive measures at all levels (educational institutions, family, medical institutions, social institutions). If we place the subjects of social prevention according to the degree of importance, then the family occupies the leading position, followed by the level of state policy, educational institutions, social protection institutions and medical institutions at the end. The analysis of the research materials allows you to group the ranking bases. In the responses of the research participants, the role of the family in the prevention of digital addiction is multifaceted. But first of all, it should be noted that the family is responsible not only as a factor in preventing digital addiction, but also as a factor in its formation (sometimes parents allow children to use gadgets too early that replaces real communication, and returning to the reality is quite difficult and painful). Interestingly, the prevention of dependence on the Network in the views of the survey participants is closely related to the formation of a special family climate. The analysis of the questionnaires showed that specialists (100\%) emphasize the importance of parent-child relations for the prevention of digital addiction. Teenagers did not agree with this statement so amicably (77\%), the remaining $23 \%$ emphasize the importance of the influence of a circle of friends on the formation of digital addiction.

According to the respondents (both specialists and pupils), educational institutions have fewer opportunities to prevent Internet addiction compared to the state and the family. All the research participants (100\%) believe that the family, the state and the educational institution can and should combine efforts in prevention. The answers to the question about professionals whose competence should be the social prevention of digital addiction were quite significantly distributed. According to the survey, the leading agents of social prevention are psychologists, psychotherapists and teachers, the least significant role of employees of internal affairs bodies. This distribution of the importance of professions is explained by the fact that respondents perceive social prevention as a social problem. 


\section{Effective areas of social prevention of digital addiction}

As part of this stage of the research, it was advisable to clarify which areas of social prevention of digital addiction, according to the respondents, are the most effective. From the point of view of specialists, the most effective will be: information in youth publications about the danger of digital addiction, its signs, prevention opportunities (100\%); organization of trainings, schools on the art of communication, increasing stress resistance, psychological improvement of personality (97\%); solving problems of free time of teenagers (development of sports, art, hobbies) (79\%); solving problems of employment of teenagers (study, improving the quality of life, volunteering) (54\%). From the point of view of teenagers, the effectiveness of working with digital addiction was distributed as follows: organization of trainings, schools on the art of communication, increasing stress resistance, psychological improvement of personality (91\%); solving problems of free time of teenagers (development of sports, art, hobbies) (89\%); solving problems of employment of teenagers (studying, improving the quality of life, volunteering) (74\%); information about the danger of digital addiction, its signs, prevention opportunities (36\%).

So, the survey participants - specialists - confirmed a high degree of involvement in the problem of social prevention, the need for various measures for students and their family members to prevent the negative consequences of addiction, and teenagers paid more attention to filling leisure time and trainings that contribute to the development of communication skills of the younger generation.

Summarizing the results of an empirical research, it should be noted that specialists who directly encounter dependent students, recognize the importance of social prevention of such digital addiction $(100 \%)$, note its similarity to other addictions, including chemical ones, have information about risk factors, manifestations, opportunities for prevention and correction of digital addiction among students. Specialists, regardless of their work profile, believe that the primary social prevention of digital addiction should be carried out in the family. However, such work at the family level is possible if there is a comprehensive non-state prevention program. The school was ranked third in terms of the degree of participation in the prevention of digital addiction. Specialists are ready to work on the prevention of digital addiction, but they are in conditions of limited information about prevention methods and possible measures, they need additional methodological support.

\section{Discussion}

Digital addiction is one of the manifestations of human interaction with the information society. Therefore, it is advisable to turn to identifying the characteristics of the information society and the impact of its essential features on the individual and society as a whole. Digital addiction is a global problem. Today, in many countries, there are special rehabilitation centers and clinics dealing with this issue. In Russia, the problem of digital addiction does not have an official status yet. During the research, it was revealed that all the interviewed specialists consider the problem of digital addiction as very important. Absolutely all the survey participants recognize the need for social prevention of digital addiction. All participants of the research believe that the family, the state and the educational institution can and should combine efforts in prevention.

To implement programs for the primary prevention of digital addiction, it is necessary to train specialists and trainers in higher educational institutions. The inclusion of young people in modern life is promoted by the centers of social support for young people. The leading areas of activity of this institution are: employment, career guidance, introduction of new social technologies - psychological rehabilitation, psychological diagnostics, psychological therapy, psychological and pedagogical prevention, psychological correction. 
In our opinion, the modern information society has both a creative and a destructive impact on the personality of the student. The destructive impact can be associated with the ethical crisis of modern information civilization, the spread of Internet influence, and the total transition to digital technologies in education.

The research materials allow us to assert that the social prevention of digital addiction is a purposeful work on the formation of social integration and adaptation skills, promoting the active involvement of students in the space of real communications, revealing their abilities in the real world. Work on social prevention, in order to increase its effectiveness, should be aimed not only at students, but also at their parents.

\section{Conclusions}

Digital addiction is a serious social, psychological, pedagogical and medical problem. It concerns mental and physical health of everyone, the nation as a whole. Depression, anxiety, general mental exhaustion, maladaptation, weakening of the immune system, diseases of eyes, spine, metabolism - this is not a complete list of the consequences of a long stay on the Internet.

Various facets of digital addiction are studied by different specialists: teachers, psychiatrists, psychologists, there are different directions of studying digital addiction, but the goal is the same - it is the prevention and correction of this condition. Addiction to the Internet, digital technologies and digital products is also defined as a disorder of volitional control that is not caused by chemicals. Unlike chemical addiction, addiction to the Internet is psychological in nature, without affecting the physiological sphere.

Thus, we can present the following typology of possible threats and risks of digital addiction for students. Threats and risks:

- to the physical health of students (visual, posture, sleep, nervous system impairment);

- to the psychological health of students (violation of the cognitive sphere, the motivational and personal sphere, the emotional sphere);

- to the social health of students (intellectual disorders, socio-cultural deviations, communication disorders).

Summarizing the results of the empirical research, it should be noted that specialists and practitioners - teachers, social workers, psychologists - state the importance of working with dependent students. First of all, the family should become an agent of such work. The tasks of the state in the social prevention of digital addiction are related to the formation of the necessary social policy aimed at solving problems in the field of employment and socio-cultural sphere of society.

In addition, the expansion of the field of use of gadgets by students (during and after study) enhances threats and risks of increasing the number of gadget-dependent students. To implement programs for the social prevention of digital addiction, it is necessary to train specialists-trainers who possess modern educational technologies, from among specialists who have the necessary knowledge on the problems of digital addiction, who have skills in organizing individual and group work with students in order to prevent digital addiction.

\section{Acknowledgment}

The research was carried out within the framework of the implementation of the scientific research "Development of psychological and pedagogical foundations for standardization of digital 
educational products/technologies" by the Moscow State Pedagogical University in 2021 at the expense of the federal budget.

\section{References}

Aibazova, M.Yu. \& Karasova, A.A. (2018). Formation of information competence of university graduates as a condition for training personnel for the digital economy. Alma Mater (Bulletin of the Higher School), 9, 5863. https://elibrary.ru/item.asp?id=35705828

Aidarbekova, K. A., Abildina, S. K., Odintsova, S. A.., Mukhametzhanova, A. O., \& Toibazarova, N. A. (2021). Preparing future teachers to use digital educational resources in primary school. World Journal on Educational Technology: Current Issues, 13(2), 188-200. https://doi.org/10.18844/wjet.v13i2.5653

Akhmetova, S.G. \& Nevskaya, L.V. (2018). The experience of introducing new technologies in higher professional education. Bulletin of the Perm National Research Polytechnic University. Socio-economic sciences, 2, 6269. https://cyberleninka.ru/article/n/18109409

Akimova, O.B. \& Shcherbin, M.D. (2018). Digital transformation of education: timeliness of educational and cognitive independence of students. Innovative projects and programs in education, 1, 27-34. https://elibrary.ru/item.asp?id=32574155

Bagautdinova, N.G. \& Nikulin, R.A. (2018). New competitive advantages in the conditions of digitalization. Innovations, 8, 80-83. https://cyberleninka.ru/article/n/18118149

Bayanova, A.R, Sabaeva, E.K., Sakhipova, Z.M., Zatsepina, M.B., Tararina, L.I., Votinov, A.A. \& Ilkevich, K.B. (2019a). Educational Environment Ecology as Factor of University Teacher Health Saving in Context of Education and Science Reforms in Modern Russia. Ekoloji, 28(107), 4937-4941. http://www.ekolojidergisi.com/article/educational-environment-ecology-as-factor-of-university-teacherhealth-saving-in-context-of-7072

Bayanova, A.R., Kuznetsov, V.V., Merculova, L.V., Gorbunova, L.N., Pervozvanskaya, O.A., Shalamova, O.O., Vorobyova, C.I. (2019b). Student Performance Interrelation with Gadget Use At Lessons. Journal of Environmental Treatment Techniques, 7(3): 432-437. https://tinyurl.com/yzkfd36t

Bayanova, A.R., Sivova, I.V., Kamasheva, Y.L., Popova, O.V., Semyanov, E.V., Shagieva, R.V. \& Yusupov, I.M. (2020). Student online services consumption: Routine practices or mistrust to digital service? Contemporary Educational Technology, 11(1), 47-54. https://eric.ed.gov/?id=EJ1234836

Bespalko, V.P. (2002). Education and training with the participation of computers (pedagogy of the third millennium). Moscow: Publishing house of the Moscow psych. - soc. Institute; Voronezh: Publishing house of

NPO "Modek".http://staff.tiiame.uz/storage/users/83/books/yqmxXrr3476uZHgsfWNel3JF3FJJqrjcPGrOekF6.p df

Bukhanovsky, A.O. (2002). Dependent behavior: clinic, dynamics, systematics, treatment, prevention. Rostov on Don: Phoenix.

Chudova, N.V. (2002). Features of the image of the "I" of the "Internet resident". Psychol. Journal, 23(1), 113-117. https://psyfactor.org/lib/chudova.htm 

products. World Journal on Educational Technology: Current Issues. 13(4), 0852-863. https://doi.org/10.18844/wjet.v13i4.6270

Dmitriev, Yu.A., Kalinina, T.V. \& Krotova, T.V. (2016). Information and communication technologies in the professional activity of a teacher of preschool education. Moscow: MPSU. https://e.lanbook.com/book/106008

Egorov, A.Yu., Kuznetsova, H.A. \& Petrova, E.A. (2005). Personality features of adolescents with Internet addiction. Vopr. psych. health of children and adolescents, 2, 20-27. http://psychildhealth.ru/2005-02.pdf\#page=58

Govorukhina, M.Yu. (2004). Virtualization of the modern world: the bifurcation of reality. Yekaterinburg, Speech. https://vestnik-mgou.ru/Articles/View/5991

Ivanov, M.S. (2007). Personal prerequisites for the formation of gaming computer addiction. Vestn. Moscow State Regional University. Psychological sciences, 1, 80-87.

Ivanova, S., \& Ivanov, O. (2020). Education in the Era of the Fourth Industrial Revolution: Development Vector, Prospects and Challenges for Russia. Space and Culture, India, 7(5), 70-79. https://www.spaceandculture.in/index.php/spaceandculture/article/view/703

Kalugina, O.A., Vasbieva, D.G., Shaidullina, A.R., Sokolova, N.L. \& Grudtsina, L.Y. (2018). ESP blended learning based on the use of smart coursebook. XLinguae, 11(2), 445-454. https://elibrary.ru/item.asp?id=35034983

Karpova, E.E. (2017). Theoretical analysis of the concept of "digital dependence" in foreign studies. Bulletin of the LSU named after A.S. Pushkin, 4, 111-117. https://cyberleninka.ru/article/n/17623477

Khomeriki, N.S. \& Smirnova, E.A. (2010). Characterological properties as risk factors for the development of Internet-dependent behavior. Hospital and outpatient psychotherapy and medical psychology: materials of the 8th all-Russian professional society, psychotherapist, conf (pp.98-104). Moscow.

Khomeriki, N.S. (2013). Internet-dependent behavior in adolescents. Features of personal properties and the formation of Internet addiction. Vestn. Psychotherapy, 46(51), 100-109. https://elibrary.ru/item.asp?id=19115069

Kornilov, Yu.V. (2017). Network and multimedia technologies as a means of optimizing the educational process. Computer science and education, 12, 107-108.

Kotlyarova, V., Rudenko, A., Yaksa, N., \& Shubina, M. (2021). Digital technologies in modern higher educational space: analysis of risks and threats. In E3S Web of Conferences (Vol. 273, p. 12050). EDP Sciences. https://doi.org/10.1051/e3sconf/202127312050

Kozlova, N.S. (2018). The relevance of online education for IT specialists. Bulletin of the Maikop State Technological University, 4, 80-85. https://cyberleninka.ru/article/n/18026999

Kvon, G.M., Vaks, V.B., Kalimullin, A.M., Bayanova, A.R., Shaidullina, A.R., Dolzhikova, A.V. \& Lapidus, N.I. (2019). Developing the Informational and Digital Environment of a University: Problem Analysis and Assessment. Eurasia Journal of Mathematics, Science and Technology Education, 15(10), 1841-1848. https://www.ejmste.com/article/developing-the-informational-and-digital-environment-of-a-universityproblem-analysis-and-assessment-7719

Lopez-Fernandez, O., \& Kuss, D. J. (2020). Preventing harmful internet use-related addiction problems in Europe: A literature review and policy options. International journal of environmental research and public health, 17(11), 3797. https://www.mdpi.com/727048

Makarov, Yu.N. (2016). The Internet as a key element of modern communication culture. Bulletin of the Adygea State University. Series 1: Regional studies: philosophy, history, sociology, law, political science, cultural studies, 1, 43-53. https://cyberleninka.ru/article/n/16677643

Nefedovskaya, L.V. (2017). The state and problems of health of student youth. Moscow: Litera.

Nguyen, T.H., Prokopyev, A.I., Lapidus, N.I., Savostyanova, S.A., \& Sokolova, E.G. (2021). Magic in healing practice: A case study in Vietnam and its philosophical assessment. XLinguae, 14(3), 164-176. 
Niankara, I., \& Niankara, A. (2020). The role of digital media in shaping youth planetary health interests in the global economy. Journal of Open Innovation: Technology, Market, and Complexity, 6(3), 49. https://www.mdpi.com/771800

Piralova, O.F., Gerasimenko, S.A., Kuznetsov, V.V., Popova, O.V., Subbotin, G.V., Kolomyts, O.G., \& Mashkin, N.A. (2020). Gaming Industry Trends in new Generation Specialist Training in University Environment. Journal of Environmental Treatment Techniques, 8(3), 1132-1135. https://tinyurl.com/u3y8bkc

Shmal, S.N. \& Zhivko, Y. (2021). Digital addiction-a problem of the XXI century. Research of young scientists: materials of the XVI International Scientific Conference (pp. 74-77). Kazan: Young Scientist.

Shmal, S.N. (2020). Pedagogy and modern society. Moscow: Publishing solutions.

Shumakova, E.V. (2011). Educational space of social networks of the Internet. Professional education. Capital, 6, 39-40. https://elibrary.ru/item.asp?id=16391808

Sorokoumova, E.A. (2019). Self-knowledge of children of the digital generation and their psychological well-being in the learning process. Information and communication technologies in the modern educational space (pp. 58-66). Moscow: 000 "Sam Polygraphist". https://elibrary.ru/item.asp?id=42633673

Spirkina, T.S. (2008). Personal characteristics of Internet users who are prone to Internet addiction. Izv. Ros. gos. ped. A.I. Herzen State University, 60, 473-478.

Temnova, L.V. \& Puchkova, E.B. (2019). Involvement in the virtual space and educational motivation of students of the digital generation. In the collection: Anthropocentric sciences: an innovative view of education and personal development. materials of the IX International Scientific and Practical Conference (pp. 421-423). https://elibrary.ru/item.asp?id=37739515

Tugun, V., Bayanova, A.R., Erdyneeva, K.G., Mashkin, N.A., Sakhipova, Z.M. \& Zasova, L.V. (2020). The Opinions of Technology Supported Education of University Students. International journal of emerging technologies in learning, 15(23), 4-14. https://www.learntechlib.org/p/218460/

Ursu, A.B. \& Khudyakov, A.V. (2009). Computer game addiction: clinic, dynamics and epidemiology. Psychotic. Health, 8, 28-32. https://elibrary.ru/item.asp?id=16345397

Ustyuzhanina, E. V., \& Evsukov, S. G. (2018). Digitalization of the educational environment: opportunities and threats. Vestnik of the Plekhanov Russian University of Economics, (1), 3-12. https://doi.org/10.21686/2413-2829-2018-1-3-12

Voiskunsky, A.E. \& Bogacheva, N.V. (2012). Cyberpsychology and its modern problems. Social computing: fundamentals, development technologies, social and humanitarian effects: materials of the First International Conference: collection of articles and theses (pp. 76-81). Moscow.

Voiskunsky, A.E. (2002). The Internet is a new field of research in psychological science. Scientific notes of the Department of General Psychology of Moscow State University, 1, 82-101. http://citeseerx.ist.psu.edu/viewdoc/download?doi=10.1.1.469.4042\&rep=rep1\&type=pdf

Yermilova, V.V., Loktionova, Y.N., Smirnov, A.V., Seregina, T.N., \& Prokopyev, A.I. (2019). The development of a personal wellbeing index -indicator of the life satisfaction. Espacios, 40(25), Article 16. https://www.revistaespacios.com/a19v40n25/19402516.html 